\title{
Effect of cataract extraction and intraocular lens implantation on nerve fibre layer thickness measurements by scanning laser polarimeter (GDx) in glaucoma patients
}

G Gazzard $1,2,3$, PJ Foster ${ }^{1,2,3}$, JG Devereux $x^{1,2}$, F Oen', PTK Chew', PT Khaw ${ }^{2,3}$ and SKL Seah ${ }^{1}$

\section{Abstract}

Purpose To assess the influence of visually significant cataract on the measurement of nerve fibre layer thickness by scanning laser polarimetry (GDx) in glaucoma patients undergoing phacoemulsification cataract extraction.

Method and Subjects All subjects with primary glaucoma participating in a prospective trial of glaucoma surgery who subsequently underwent cataract extraction were eligible. A single trained observer using the GDx nerve fibre layer analyser (LDT) performed pre- and post-operative measurements of nerve fibre layer thickness (NFLT). NFLT parameters, best-corrected LogMAR visual acuity, and automated visual fields were assessed before and after phacoemulsification cataract extraction with implantation of an acrylic intraocular lens. Results A total of 49 subjects were assessed: 22 (45\%) had POAG and 29 (55\%) PACG; all were Asian (36 (73\%) were Chinese), with mean age 67.1 ( $\pm 7.6 \mathrm{SD})$ and mean 'LOCS III' lens opacity grading $11.4( \pm 3.1 \mathrm{SD})$. Visual acuity significantly improved (mean LogMAR 0.5 vs $0.15, P<0.0001)$. Corrected pattern standard deviation (6.1 vs $6.4, P=0.2)$ and mean deviation $(-17.7 \mathrm{~dB}$ vs $-\mathbf{1 7 . 0} P=\mathbf{0 . 9 1})$ were little changed after cataract removal. Pseudo-phakic measurements of NFLT were significantly different from pre-op values. Measures of absolute thickness (including the average thickness, ellipse, ellipse average, superior and inferior averages, superior integral) were significantly greater than preoperative values (all $\boldsymbol{P}<0.01$ ), whereas ratios and measures of symmetry (symmetry, superior/nasal) were unchanged (all $P>0.1$ ) and 'the number' was smaller $(P=0.04)$. Differences in measured NFLT were most strongly correlated with posterior subcapsular cataract (average thickness, $P=0.01$ ).

Conclusions Removal of cataract resulted in greater absolute measurements of NFLT but ratio values were unchanged. Scanning laser polarimetry measurements can change significantly after cataract extraction. New baseline measurements may be required. Eye (2004) 18, 163-168. doi:10.1038/ sj.eye. 6700600

Keywords: glaucoma; GDX; scanning laser polarimetry; cataract

Introduction

Glaucomatous optic neuropathy is characterised by the progressive loss of ganglion cells and accompanying optic disc and retinal nerve fibre layer (NFL) changes. Alterations in visual field sensitivity are the corresponding functional measure of ganglion cell function but there may be a substantial loss of axons before visual field changes develop. ${ }^{1}$

The detection of changes over time in visual function or in anatomy is the mainstay of the follow-up and treatment of glaucoma. However,
${ }^{1}$ Singapore National Eye Centre, Singapore

${ }^{2}$ Institute of Ophthalmology and Moorfields Eye Hospital London, England, UK

${ }^{3}$ Singapore Eye Research Institute, Singapore

Correspondence:

G Gazzard

Department of Wound

Healing Institute of Ophthalmology

Bath Street

London EC1V 29EL, UK Tel: + 442076086906 Fax: + 442072503207 E-mail: gus@ gazzard. demon.com

Received: 1 November 2002 Accepted: 26 March 2003

Funding and support by Singapore National Medical Research Council NMRC/ 0044/1994, Singapore National Eye Centre, and Medical Research Council (UK) G9330070 (Professor Khaw)

Commercial relationships or conflict of interest: None 
the inherent test-retest variability of a psychophysical measure such as visual field testing makes the reliable detection of change in even established scotomata ${ }^{2,3}$ difficult and is highly patient dependent. ${ }^{4}$ Examination of the optic disc and NFL by careful stereoscopic biomicroscopy permits the detection of morphological changes in anatomy before perimetry shows changes in visual function. ${ }^{5,6}$ Quantification of objective measurements of these structural alterations may allow even greater sensitivity in the detection of progressive glaucomatous loss. ${ }^{7,8}$ Scanning laser polarimetry (SLP) gives a reproducible, ${ }^{9-11}$ objective in vivo measurement of the thickness of the NFL, based on the alteration it causes in the polarisation of light passed through it (retardation). ${ }^{12}$ It is thought that neuronal microtubules act as naturally polarising, birefringent structures, and the degree of retardation is proportional to the NFL thickness (NFLT).

Longitudinal assessments of the stability of NFLT must account for both age related ganglion cell loss ${ }^{12-15}$ and the alteration of polarising structures in the path of the SLP. ${ }^{16-18}$ The crystalline lens is a weakly polarising structure and many patients with glaucoma will develop cataract following glaucoma surgery or with increasing age. Previous studies have looked at the effects of cataract extraction on the measurement of the NFL with conflicting results. ${ }^{19-23}$ Both Kremmer et $a l^{22}$ and Chiba et $a l^{19,20}$ found that dense cataract led to an underestimation of NFLT, whereas Park et $a l^{23}$ found unpredictable changes with intraocular lens (IOL) implantation and Collur et $a l^{24}$ suggested that there was no change after cataract extraction.

The aim of this study was to evaluate the effects of cataract extraction on the measurement of NFLT in a population of moderate to severe glaucomatous subjects using SLP (GDx, Laser Diagnostic Technologies, San Diego, CA, USA).

\section{Methods}

Subjects enrolled in a prospective, randomised, placebocontrolled trial of the use of intraoperative 5-fluorouracil in glaucoma filtering surgery in South East Asia were included. This study was granted ethical approval by The Ethical Review Committee of Singapore National Eye Centre, acting for The Ministry of Health of The Republic of Singapore. Written informed consent was obtained from all participants in their own language with an interpreter where necessary.

The inclusion criteria were as follows: intraocular pressure (IOP) greater than $21 \mathrm{mmHg}$ on at least one occasion, reduction of the neuroretinal rim width to less than or equal to 0.1 of the cup: disc ratio or a glaucomatous optic disc in the opinion of a fellowship- trained glaucoma specialist on clinical disc assessment, and a visual field defect consisting of at least two points reduced by $>5 \mathrm{~dB}$ or one point reduced by $>10 \mathrm{~dB}$ below age-specific threshold.

Exclusion criteria were: age less than 30 years, previous intraocular or conjunctival surgery, any nonlenticular axial media opacity, corneal oedema, and other ocular or systemic pathology, which might result in a visual field defect (including diabetic retinopathy or age-related macular degeneration).

Data were collected regarding one eye only of each subject. During preoperative work-up, a full ophthalmic examination was carried out. The degree of lens opacity (nuclear opacity and colour, cortical and posterior subcapsular opacities) was graded by clinical observation at a slit lamp using standard photographs of the LOCS III scheme. ${ }^{25}$

NFL measurements were performed by scanning laser polarimeter ("GDx"; Laser Diagnostic Technologies, San Diego, CA, USA; GDx software version 2.0.09) by a single experienced individual under ambient room lighting. All GDx measurements were taken within 8 weeks of surgery on each occasion; specifically, postoperative measurements were made at least 4 weeks after cataract surgery - after any postoperative corneal oedema, if any, had settled. The principles are well described elsewhere. ${ }^{26}$ Standard $15^{\circ} \times 15^{\circ}$ measurements, which passed the internal software quality control, were made at each visit through an undilated pupil and a mean image used for analysis. The measurement ellipse was positioned at the same position at the second examination by reference to the retinal landmarks in the initial image. Image analysis was carried out using the GDx software. We compared the pre- and post-operative output values derived from the GDx software, as our aim was to establish the impact of cataract extraction on the use of GDx in a clinical setting.

Phacoemulsification cataract extraction was performed by one of two senior consultant surgeons via a temporal or superior clear corneal incision, as dictated by the orientation of existing astigmatism and/or the position and extent of trabeculectomy bleb. All eyes underwent in-the-bag implantation of a single type of foldable acrylic lens ("AcrySof", MA60 BD, Alcon).

Visual field examination was carried out using a static automated perimeter (Model 750, Zeiss Humphrey, San Leandro, CA, USA). A minimum of two visual field tests were carried out on different days using the 24-2 program, requiring that the test was completed with $<33 \%$ false positives, $<33 \%$ false negatives, and $<20 \%$ fixation losses. If the mean defect in these tests differed by more than $2 \mathrm{~dB}$, further tests were carried out until two test results with a mean deviation (MD) within $2 \mathrm{~dB}$ had been obtained. 
Differences in mean values of parametric data between individuals before and after intervention were examined using a paired sample $t$-test. For nonparametric data, a Mann-Whitney U-test was used to compare means and the Wilcoxon sign rank test for the distribution of two related variables. $\chi^{2}$ was used for the analysis of categorical variables. A value of $P<0.05$ was taken as significant; where multiple tests were performed, a Bonferroni correction was applied.

\section{Results}

A total of 64 cases were eligible, of which 15 cases had cataract that prevented GDx imaging. A total of 49 subjects were therefore analysed, 22 with POAG and 29 with PACG; 23 were left eyes and 26 right. Table 1 summarises the demographic and ophthalmological characteristics of the subjects for whom data are presented. After standard phacoemulsification and insertion of an acrylic IOL, visual acuity improved (mean LogMAR 0.5 vs $0.15, P<0.0001)$, and corrected pattern standard deviation (CPSD) (6.07 vs 6.38, $P=0.2)$ and MD ( -17.7 vs $-17.0 \mathrm{~dB}, P=0.9)$ were unchanged (Table 2). IOP was not significantly different postoperationally, (13.2 (SD 3.2) vs $14.1 \mathrm{mmHg}$ (SD 3.4), $P=0.4$ ).

Table 3 shows and compares the mean values for the SLP parameters before and after cataract extraction, with the values that were significantly different on paired $t$ test indicated. Many, but not all, parameters of pseudophakic NFLT measurements were significantly different from phakic measurements (Table 3).

Differences between SLP measures of NFLT before and after cataract extraction were correlated with the grade of

Table 1 Patient characteristics

\begin{tabular}{lc}
\hline $\begin{array}{l}\text { Number of subjects } \\
\text { Age (years) } \pm \text { SD } \\
\text { (range) }\end{array}$ & $67.1 \pm 7.6$ \\
Race & $(51.0-79.9)$ \\
$\quad$ Chinese & $36(73 \%)$ \\
Malay & $6(12 \%)$ \\
Indian & $7(14 \%)$ \\
Gender & \\
$\quad$ Males & $29(59 \%)$ \\
Females & $20(41 \%)$ \\
& \\
Axial length (mm) $\pm S D$ & $23.1 \pm 1.27$ \\
$\quad$ (range) & $(20.4-26.5)$ \\
& \\
LOCS (range) & \\
Nuclear colour & $4.4(2-6)$ \\
Nuclear opalescence & $4.2(2-6)$ \\
Cortical opacity & $0.9(0-5)$ \\
Posterior subcapsular & $1.2(0-5)$ \\
\hline
\end{tabular}

LOCS=lens opacity cataract score. posterior subcapsular cataract (Spearman correlation, $r_{\mathrm{S}}$ ), but not with nuclear colour, nuclear opalescence or cortical cataract (eg for PSCLO LOCS score and average thickness, $r_{\mathrm{S}}=0.35, P=0.006$; superior average, $r_{\mathrm{S}}=0.34$, $P=0.008$; inferior average, $r_{\mathrm{S}}=0.32, P=0.01$; ellipse average, $\left.r_{\mathrm{S}}=0.38, P=0.004\right)$. This was true for 'absolute values' of NFLT but not ratio measures (eg for PSCLO LOCS score and superior ratio, $r_{\mathrm{S}}=0.14, P=0.16$; inferior ratio, $\left.r_{\mathrm{S}}=0.14, P=0.16\right)$. There was a wide range of changes in the different parameters, and the change in one parameter did not necessarily predict the behaviour of another. A comparison of the PACG and POAG eyes (excluding two non-POAG/PACG cases) showed no significant difference in the change in postoperative measurement between the two diagnoses.

\section{Discussion}

Measures of absolute thickness (including the superior and inferior deviation, average thickness, ellipse average, superior and inferior averages) were significantly greater after cataract extraction and implantation of an IOL $(P<0.01)$. In contrast, ratios and measures of symmetry (symmetry, superior/nasal ratio) were less different with only small increases of borderline significance. 'The number', which is a composite value derived by neural network from many other parameters ${ }^{26}$ for use in glaucoma detection, was lower after cataract extraction.

Progressive changes in lens opacity are common in glaucoma subjects as consequences of both age and filtering surgery. Glaucoma is a slowly progressive optic neuropathy in which reliable detection of changes in function and anatomy over time is required for management decisions. It would thus be useful to know how developing cataract and its treatment might affect longitudinal measures of potential progression of glaucomatous damage.

Our results suggest that the removal of a cataractous lens can increase the apparent NFLT. This could be because of a reduction of the retardation by the cataract, an increase caused by the substance of the IOL, or a combination of both. A change in the apparent thickness is a more biologically plausible explanation than a true increase in NFLT after cataract extraction; however this would be a theoretically possible explanation of our findings. One study suggesting that NFLT changed after trabeculectomy ${ }^{27}$ attributed their results to a decrease in IOP; however, our subjects showed no change in mean IOP before and after surgery. The marked increase in absolute values in the presence of relatively small changes of ratio values further suggests that this is a cataract-related effect on measurement rather than any true change in NFL anatomy. One important consequence of this comparative stability of the 'ratio' 
Table 2 Global indices before and after cataract surgery

\begin{tabular}{lccc}
\hline Global indices & Before Phaco' Mean $\pm S D$ (range) & After Phaco' Mean \pm SD (range) & P \\
\hline Mean deviation (MD) & $-17.38 \pm 8.05$ & $17.74 \pm 8.11$ & 0.91 \\
& $(-31.58$ to -5.05$)$ & $(31.47$ to 5.14$)$ & $7.27 \pm 3.24$ \\
Pattern standard deviation (PSD) & $6.71 \pm 3.11$ & $(1.84$ to 13.22$)$ & 0.03 \\
& $(1.79$ to 12.74$)$ & $2.66 \pm 1.69$ & \\
Short term fluctuation & $2.09 \pm 1.29$ & $(0.0$ to 7.88$)$ & 0.02 \\
& $(0.0$ to 6.26$)$ & $6.38 \pm 3.49$ & 0.20 \\
Corrected PSD (CPSD) & $6.07 \pm 3.37$ & $(0.0$ to 12.95$)$ & \\
& $(0.0$ to 12.66$)$ & & \\
\hline
\end{tabular}

Table 3 Pre- and postphaco' values of nerve fibre layer measurement by scanning laser polarimetry (GDx)

\begin{tabular}{|c|c|c|c|c|c|c|c|}
\hline \multirow[t]{2}{*}{ Parameters } & \multicolumn{2}{|c|}{ Preop } & \multicolumn{2}{|c|}{ Postop } & \multicolumn{2}{|c|}{ Pre/postop' } & \multirow[t]{2}{*}{ P-value } \\
\hline & Mean & $S D$ & Mean & $S D$ & Difference & Range & \\
\hline Superior deviation & -26.94 & 14.26 & -23.35 & 16.91 & 3.58 & -29.0 to 21.0 & 0.01 \\
\hline Temporal deviation & 4.50 & 14.08 & 5.04 & 17.95 & 0.54 & -20.0 to 37.0 & 0.71 \\
\hline Nasal deviation & 7.27 & 15.13 & 8.48 & 16.40 & 1.21 & -24.0 to 28.0 & 0.38 \\
\hline Inferior deviation & -19.63 & 14.37 & -14.31 & 19.56 & 5.31 & -50.0 to 29.0 & 0.009 \\
\hline Symmetry & 0.93 & 0.14 & 0.92 & 0.10 & -0.02 & -0.2 to 0.5 & 0.47 \\
\hline Superior ratio & 1.39 & 0.33 & 1.50 & 0.49 & 0.11 & -1.9 to 0.6 & 0.06 \\
\hline Inferior ratio & 1.50 & 0.34 & 1.63 & 0.52 & 0.13 & -2.3 to 0.5 & 0.03 \\
\hline Superior nasal ratio & 1.24 & 0.20 & 1.28 & 0.23 & 0.04 & -0.5 to 0.5 & 0.1 \\
\hline Maximum modulation & 0.68 & 0.25 & 0.82 & 0.43 & 0.14 & -2.3 to 0.4 & 0.03 \\
\hline Ellipse modulation & 0.99 & 0.46 & 1.32 & 0.60 & 0.32 & -2.7 to 0.5 & $<0.0001$ \\
\hline The 'number' & 82.76 & 15.58 & 78.73 & 18.25 & -4.02 & -26.0 to 36.0 & 0.04 \\
\hline Average thickness & 55.02 & 10.94 & 58.00 & 13.62 & 2.98 & -29.0 to 18.0 & 0.01 \\
\hline Ellipse average & 56.04 & 11.46 & 59.24 & 14.32 & 3.20 & -30.0 to 17.0 & 0.007 \\
\hline Superior average & 56.39 & 11.76 & 59.98 & 14.77 & 3.59 & -29.0 to 17.0 & 0.003 \\
\hline Inferior average & 60.73 & 13.86 & 66.04 & 17.01 & 5.31 & -39.0 to 12.0 & $<0.0001$ \\
\hline Superior integral & 0.19 & 0.05 & 0.21 & 0.05 & 0.02 & -0.1 to 0.1 & $<0.0001$ \\
\hline
\end{tabular}

Values derived as ratios are in italics.

$P$-values for paired ' $t$ '-tests: bold is significant after a Bonferroni correction for multiple tests.

values is that if changes in such measures are present, they are more likely to reflect true alterations in anatomy than be due to progressive lens opacity or surgery. The changes in absolute values were correlated with at least one grading of cataract severity-PSCLO. Again this would suggest that the effects are from the cataract itself and not purely a result of polarisation changes induced by the IOL substance.

The decrease in "the number" has consequences for the use of the GDx in the detection of glaucoma. This value is derived via a neural network from various scan parameters; the higher the number, the greater the chance of an individual having glaucoma. ${ }^{26}$ Cataract extraction reduced the magnitude of this figure in these subjects who had well documented moderate to advanced glaucoma. This suggests that in a pseudophakic individual, the likelihood of glaucoma, at a given value of the number, might be higher than if phakic. More work on more borderline 'suspect' cases will be required to evaluate the effects of pseudophakia on this.
Our study found a surprisingly small change in MD after cataract extraction, while the PSD increased. An increase in PSD after cataract extraction has been previously described by Chen and Budenz, ${ }^{28}$ and may be because of an 'unmasking' of variation in sensitivity across the visual field upon removal of the lens opacity. The small change in MD might reflect the overall relative severity of these subjects in whom most of the reduction in $\mathrm{MD}$ is due to glaucomatous damage rather than the lens opacity. It could also however represent an underlying deterioration of visual fields concurrent with surgery. However, any such potential progression of glaucomatous damage between examinations would be expected to reduce the NFLT, not increase it. Were glaucomatous nerve damage to progress during our follow-up period it would reduce the magnitude of these findings and as such cannot explain our results: although we cannot exclude that this was a concurrent event.

A commonly discussed limitation of the SLP is the interindividual variation in readings because of differences in corneal polarisation. ${ }^{16,29-32}$ However, these 
have been shown to be stable over time $\mathrm{e}^{33}$ and, as it is the intraindividual changes that are considered here, do not affect our conclusions. It is conceivable that the cataract incision itself might affect polarisation, although in one study neither corneal thickness nor curvature did so. ${ }^{32}$ Further studies would be required to determine whether such a shift does occur. It should also be noted that these results are not because of an optical magnification effect caused by IOL insertion, as retardation of polarisation is independent of magnification.

Our findings agree with those of a recent report that also assessed the NFLT measurements before and after cataract extraction in 39 eyes undergoing phacoemulsification with a variety of techniques and lenses. ${ }^{23}$ Park et al $^{23}$ describe a significant change in $24 \%$ of 39 eyes examined, but saw both increases and decreases in measured NFLT. Their consistent finding was of an increase in NFLT readings, as we found, after Acrysof acrylic lens implantation. Our study differs from theirs in that we examined a sample of moderate to severe glaucoma subjects (mean MD -17.38, range -31.58 to -5.05 ), whereas theirs were predominantly nonglaucomatous clinic 'normals'. Our sample may more closely reflect the subjects in whom regular nerve fibre layer measurements would be used. These would be expected to have thinner NFL. Yet even in this group, in which absolute values are smaller, we found a clinically significant difference in measurement after cataract removal. A further study also showed small increases in measured NFLT after cataract extraction and implantation of HEMA or PMMA lenses in normal subjects, ${ }^{22}$ which would fit with our results.

\section{Conclusions}

Our study suggests that SLP may be significantly affected by lens extraction and acrylic IOL insertion. This would suggest that new baseline measurements are advisable after cataract surgery. Ratio measurements or modulation parameters rather than absolute thickness measurements may be a more reliable measure than the absolute values in the presence of progressive cataract.

\section{References}

1 Quigley HA, Addicks EM, Green WR. Optic nerve damage in human glaucoma. III. Quantitative correlation of nerve fibre loss and visual field defect in glaucoma, ischaemic optic neuropathy, disc oedema and toxic neuropathy. Arch Ophthalmol 1982; 100: 135-139.

2 Antón A, Maquet JA, Mayo A, Tapia J, Pastor JC. Value of logistic discriminant analysis for interpreting initial visual field defects. Ophthalmology 1997; 104: 525-531.
3 Chauhan BC, Drance SM, Douglas GR. The use of visual field indices in detecting changes in the visual field in glaucoma. Invest Ophthalmol Vis Sci 1990; 31: 512-520.

4 Keltner JL, Johnson CA, Quigg JM, Cello KE, Kass MA, Gordon MO. Confirmation of visual field abnormalities in the Ocular Hypertension Treatment Study. Ocular Hypertension Treatment Study Group. Arch Ophthalmol 2000; 118: 1187-1194.

5 Sommer A, Katz J, Quigley HA, Miller NR, Robin AL, Richter RC et al. Clinically detectable nerve fibre atrophy preceeds the onset of glaucomatous visual loss. Arch Ophthalmol 1990; 109: 77-83.

6 Kamal DS, Bunce C, Hitchings RA. Use of the GDx to detect differences in retinal nerve fibre layer thickness between normal, ocular hypertensive and early glaucomatous eyes. Eye 2000; 14: 367-370.

7 Kamal DS, Viswanathan AC, Garway-Heath DF, Hitchings RA, Poinoosawmy D, Bunce C. Detection of optic disc change with the Heidelberg retina tomograph before confirmed visual field change in ocular hypertensives converting to early glaucoma. Br J Ophthalmol 1999; 83: 290-294.

8 Ugurlu S, Hoffman D, Garway-Heath DF, Caprioli J. Relationship between structural abnormalities and shortwavelength perimetric defects in eyes at risk of glaucoma. Am J Ophthalmol 2000; 129: 592-598.

9 Hoh ST, Ishikawa H, Greenfield DS, Liebmann JM, Chew SJ, Ritch R. Peripapillary nerve fiber layer thickness measurement reproducibility using scanning laser polarimetry. J Glaucoma 1998; 7: 12-15.

10 Colen TP, Tjon-Fo-Sang MJ, Mulder PG, Lemij HG. Reproducibility of measurements with the nerve fiber analyzer (NfA/GDx). J Glaucoma 2000; 9: 363-370.

11 Kook MS, Sung K, Park RH, Kim KR, Kim ST, Kang W. Reproducibility of scanning laser polarimetry (GDx) of peripapillary retinal nerve fiber layer thickness in normal subjects. Graefes Arch Clin Exp Ophthalmol 2001; 239: 118-121.

12 Weinreb RN, Shakiba S, Zangwill L. Scanning laser polarimetry to measure the nerve fiber layer of normal and glaucomatous eyes. Am J Ophthalmol 1995; 119: 627-636.

13 Lee VW, Mok KH. Nerve fibre layer measurement of the Hong Kong Chinese population by scanning laser polarimetry. Eye 2000; 14: 371-374.

14 Poinoosawmy D, Fontana L, Wu JX, Fitzke FW, Hitchings RA. Variation of nerve fibre layer thickness measurements with age and ethnicity by scanning laser polarimetry. $\mathrm{Br} J$ Ophthalmol 1997; 81: 350-354.

15 Sens FM, Mojon DS, Fleischhauer J, Bergamin O, Bohnke M. Measuring nerve fiber thickness with laser scanning polarimetry in aging. Klin Monatsbl Augenheilk 1998; 212: 261-263.

16 Choplin NT. Effect of corneal polarization axis on assessment of retinal nerve fiber layer on thickness by scanning laser polarimetry. Am J Ophthalmol 2001; 131: 528-529.

17 Choplin NT, Schallhorn SC. The effect of excimer laser photorefractive keratectomy for myopia on nerve fiber layer thickness measurements as determined by scanning laser polarimetry. Ophthalmology 1999; 106: 1019-1023.

18 Gurses-Ozden R, Pons ME, Barbieri C, Ishikawa H, Buxton $\mathrm{DF}$, Liebmann JM et al. Scanning laser polarimetry measurements after laser-assisted in situ keratomileusis. Am J Ophthalmol 2000; 129: 461-464. 
19 Chiba T, Kogure S, Tsukahara S. Influence of cataract on scanning laser polarimetry. Nippon Ganka Gakkai Zasshi-Acta Soc Ophthalmol Jpn 2000; 104: 626-630.

20 Chiba T, Kogure S, Tsukahara S. Influence of cataract on scanning laser polarimetry. J Ophthalmol 2000; 45(2): 202-203.

21 Hoh ST, Greenfield DS, Liebmann JM, Hillenkamp J, Ishikawa $\mathrm{H}$, Mistlberger A et al. Effect of pupillary dilation on retinal nerve fiber layer thickness as measured by scanning laser polarimetry in eyes with and without cataract. J Glaucoma 1999; 8: 159-163.

22 Kremmer S, Pflug A, Heiligenhaus A, Fanihagh F, Steuhl KP. Laser scanning topography and polarimetry with implantation of intraocular lenses before and after cataract surgery. Klin Monatsbl Augenheilk 1999; 214: 378-385.

23 Park RJ, Chen PP, Karyampudi P, Mills RP, Harrison DA, Kim J. Effects of cataract extraction with intraocular lens placement on scanning laser polarimetry of the peripapillary nerve fiber layer. Am J Ophthalmol 2001; 132: 507-511.

24 Collur S, Carroll AM, Cameron BD. Human lens effect on in vivo scanning laser polarimetric measurements of retinal nerve fiber layer thickness. Ophthalmic Surg Lasers 2000; 31: 126-130.

25 Chylack Jr LT, Wolfe JK, Singer D, Leske MC, Bullimore MA, Bailey IL et al. Lens opacity classification system III. Arch Ophthalmol 1993; 111: 831-836.

26 Weinreb RN, Zangwill L, Berry CC, Bathija R, Sample PA. Detection of glaucoma with scanning laser polarimetry. Arch Ophthalmol 1998; 116: 1583-1589.
27 Yamada N, Tomita G, Yamamoto T, Kitazawa Y. Changes in the nerve fiber layer thickness following a reduction of intraocular pressure after trabeculectomy. J Glaucoma 2000; 9(5): 371-375.

28 Chen PP, Budenz DL. The effects of cataract extraction on the visual field of eyes with chronic open-angle glaucoma. Am J Ophthalmol 1998; 125: 325-333.

29 Greenfield DS, Knighton RW, Feuer WJ, Schiffman JC, Zangwill L, Weinreb RN. Correction for corneal polarization axis improves the discriminating power of scanning laser polarimetry. Am J Ophthalmol 2002; 134: 27-33.

30 Greenfield DS, Knighton RW, Huang XR. Effect of corneal polarization axis on assessment of retinal nerve fiber layer thickness by scanning laser polarimetry. Am J Ophthalmol 2000; 129: 715-722.

31 Greenfield S, Knighton RW, Huang X. Effect of corneal polarization axis on assessment of retinal nerve fiber layer thickness by scanning laser polarimetry. Am J Ophthalmol 2001; 131: 403-404.

32 Weinreb RN, Bowd C, Greenfield DS, Zangwill LM. Measurement of the magnitude and axis of corneal polarization with scanning laser polarimetry. Arch Ophthalmol 2002; 120: 901-906.

33 Greenfield DS, Knighton RW. Stability of corneal polarization axis measurements for scanning laser polarimetry. Ophthalmology 2001; 108: 1065-1069. 